\title{
The National Health Service and the internet
}

Simon de Lusignan MSc MRCGP

J R Soc Med 2003;96:490-493

'As a general practitioner piloting 21 st century electronic links across the healthcare system, you get a thrill each time you send a prescription direct to the pharmacist. Then you find that, because pharmacists now telephone holders of uncashed prescriptions, your drugs bill is up by $20 \%$. Equally, some of your patients send thoughtful emails, but you need nearly two hours a week to respond properly.' - Wyatt and Keen ${ }^{1}$

Investment by the National Health Service (NHS) in internet infrastructure will open new opportunities for patients and clinicians. The initial funding was prompted by the 1998 report Information for Health, ${ }^{2}$ and an additional $£ 500$ million is promised over the next few years. ${ }^{3}$ Modernization of the infrastructure ${ }^{4}$ includes not only better access to information sources ${ }^{5-7}$ but also electronic transmission of prescriptions, electronic appointment booking and enhanced medical records. But how will patients and clinicians use the internet? The effects of this IT (information technology) revolution on practice and organization are not all predictable, ${ }^{8,9}$ as Wyatt and Keen indicated in the above quotation. ${ }^{1}$

In this review I look at how the internet is being used at present and try to identify emerging patterns. The paper is based on material obtained from a Medline search under the terms NHS AND Internet, Internet AND Outcomes AND UK, and Internet AND patient AND Information AND UK. This yielded 213 papers, in 47 of which the abstracts referred either to use of the internet in clinical care or to sites designed to improve the quality of care. The websites of the Department of Health and the NHS Information Authority were also searched with these terms. To obtain a consumer perspective, I used the Google and Yahoo search engines to identify the most popular websites.

\section{STRUCTURES}

Investments by the NHS to improve access to internet technology and online information (for patients as well as clinicians) are being made in communications infrastructure, hardware and software licences. ${ }^{10}$ How the infrastructure is to be set up is being determined centrally, and

Primary Care Informatics, Department of Community Health Sciences, Hunter Wing, St George's Hospital Medical School, London SW17 ORE, UK national contracts will be awarded. A start has been made on the measures necessary to ensure confidentiality of patients' data. The NHS has set up three core information services:

- The 'Official NHS Gateway', also known as dot-NHS, dot-UK. ${ }^{7}$ This has links to information about the services provided by the NHS and to league tables and star ratings

- NHS Direct-on-line, ${ }^{5}$ designed to provide clinical information for patients

- National electronic Library for Health, ${ }^{6}$ a portal to evidence-based medicine for professionals.

The three differ in design and lack any common indexing system or search mechanism; consequently the user will have difficulty in merging the resources they offer.

Outside the NHS there are few fixed structures, with the notable exception of those provided by the US National Library of Medicine (NLM). The NLM's range of biotechnology resources includes PubMed Medline, with its searchable archive of over 11 million journal citations, material on the genome and genetic disorders, and access to PubMed Central (online full-text access to over 100 journals). In addition, links to free medical journals are available via FreeMedicalJournals.com, ${ }^{11}$ which lists over 1000 journals, though for some the content is included only in part or two years after original publication.

There have also been attempts to offer guidance on the quality of health websites. One of the best known is Healthon-the-Net (HoN), which offers principles for assessing the sites; however, these are largely about the process whereby the content is assembled rather than the quality of individual parts. Despite many attempts, a single method for identifying and labelling sites with good-quality information has proved elusive. ${ }^{12}$

\section{PROCESSES}

\section{Information source for patients}

For patients, qualities that make a site credible are reputable source, professional design, scientific or official touch, the style of writing, and ease of use. A UK website Judge Health ${ }^{13}$ has been established to help laypersons obtain and critically appraise health information from the internet. With such guidance, users may avoid the pitfalls 
of well designed official-looking sites that offer misleading information.

From the evidence examined, only a minority of patients at present use the internet as their preferred information source on health, though in most surveys about half have internet access. Rokade et al. ${ }^{14}$ questioned ENT outpatients and found that only one-third of those with access had consulted the internet before attending; evidently, most still relied for information on their GP. Among patients attending a cognitive function clinic Larner ${ }^{15}$ found a higher level of internet use for health information (26\%), and stressed the importance of asking what sites the patients were using, so as to help them with their search strategies. Similar messages have appeared in nursing journals: both Timons $^{16}$ and Greenwood ${ }^{17}$ emphasize the contribution of such help to patient 'empowerment'. Moreover, unless clinicians ask what information patients have already looked up, they are unlikely to find out. For example, a sizeable proportion of urology patients proved to be using 'alternative' remedies, having discovered about them from the internet; yet most had not told their urologist or GP. ${ }^{18}$ Among patients of paediatric outpatients, Tuffrey and Finlay ${ }^{19}$ found that 22\% (nearly half of those with access) had looked for information on the internet. What they add is that $6 \%$ had had a health professional suggest the internet, and when this had happened the parents were three times more likely to use it. Of those who had consulted the internet before an appointment, all but a few found it useful. In other areas of paediatrics the proportions of parents consulting the internet are closely similar - chronic renal failure 23\%, ${ }^{20}$ paediatric surgery $24 \% .^{21}$

What can be said of the sites themselves? Smart and Burling systematically reviewed the information available online for patients about radiology procedures. ${ }^{22}$ Their verdict was that the information was helpful but often incomplete; moreover, some of it would present difficulties for people of limited literacy. More encouraging results emerged from an exit survey of those who use the NHS Direct touch-screen kiosks: two-thirds said that the kiosks answered their questions, with only $16 \%$ feeling that they had more to ask. ${ }^{23}$ NHS Direct-on-line ${ }^{5}$ is indeed the only official NHS site that features in surveys of the top internet sites. It is joined among the top fifty (according to a commercial website rating company) ${ }^{24}$ by Patients UK. ${ }^{25}$ This is a collection of over 500 patient advice leaflets written by two GPs, distributed free via this site. The top UK health sites (listed in Internet Magazine, ${ }^{26}$ for example) are dominated by information sites, and have more to say on issues of health and fitness than about illnesses and medical disorders. A site that goes beyond information is NetDoctor; ${ }^{27}$ this offers interactive reminders on request to those taking oral contraceptives, as well as providing the opportunity to ask a doctor a question online. Another, Contact a Family, ${ }^{28}$ provides extensive information on a range of rare conditions and enables affected families to get in touch for mutual support.

\section{Information source for professionals}

In UK primary care, $69 \%$ of GPs and $70 \%$ of practice nurses use NHSnet and the internet in their work. The main constraints are lack of time, lack of skill and worries about reliability. Half are willing to recommend the internet to patients. ${ }^{29}$ But often it is the patient who makes the first move. Most GPs have had patients arrive for their appointment with information gathered from the internet, and in many instances this information comes fresh to the GP. Also, the responses of GPs are likely to differ. In one survey professionals within a single practice reported different degrees of access to information sources, ${ }^{30}$ and this observation probably reflected varying competence rather than different facilities. The sad fact is that some of the material will be of poor quality: there is no easy way to completely avoid low-quality material, even for NHS Direct-on-Line, ${ }^{31}$ though fortunately as yet there is no evidence that unrestricted consumer access to health websites does harm. ${ }^{32}$

How much does use of the internet change practice? There are data on how certain of the services are used - for example, toxicology information ${ }^{33}$ or the Primary Care National electronic Library for Health ${ }^{34}$ — but there is scant evidence on the extent to which their use changes practice. Nevertheless, observations on the use of an internet resource can provide useful secondary information on the kind of information that is wanted. For instance, of 60281 accesses to the product database of a toxicology site the greatest number (7291) were for paracetamol. Ecstasy was at number seven. ${ }^{35}$

Another facility offered by the internet is a form of open review, whereby users and potential users comment on what is proposed. McNulty et al. have reported the feedback that they received about antibiotic guidelines, and how they were able to improve these guidelines as a result. ${ }^{36}$ Whether the internet can be used as a medium for learning new ways of practising is more doubtful. Online educational materials are available, ${ }^{37,38}$ and online interactive internet workshops are claimed to be useful; ${ }^{39}$ those who produce electronic libraries have started to talk about them as knowledge services. ${ }^{40}$ However, just making things electronic is not the whole answer. ${ }^{41}$ If healthcare professionals are to learn and change, the human interactions demand attention. ${ }^{42}$ Powerful electronic technologies carry the risk of information overload, and those who wish to flourish in this new environment must develop a knowledge management strategy. ${ }^{43}$ 


\section{DISCUSSION}

From this review I conclude that patients and clinicians use the internet in inconsistent and suboptimal ways, but the lack of outcome-based studies hampers identification of ideal strategies. ${ }^{4-46}$ The 'dot-com revolution' should have taught us not to over-claim the potential of new technologies, ${ }^{47}$ and how IT implementations can have unexpected results for organizations and individuals. ${ }^{9}$ Within the NHS the current programme, with its emphasis on infrastructure and basic information services, offers enormous scope for creativity and experimentation. ${ }^{48}$ For existing patients and clinicians I offer the following suggestions:

- Be familiar with the commonly used internet sites relevant to your specialty

- Use these sites regularly for information to help solve problems and to stay up-to-date with current health beliefs as well as disease management

- Always ask patients whether they have looked up information before the consultation and whether they wish to discuss it

- Be ready to suggest a more effective search strategy when a patient has been unable to obtain relevant information

- When a patient lacks confidence in searching for health information on the internet, point him or her to the Judge Health website ${ }^{13}$

- Dispense an information prescription: advice on where to find authoritative information (not necessarily from the internet) should be part of every consultation.

Acknowledgment I thank the Young Fellows and Students of RSM who invited me to talk at their New Media, New Medicine conference.

\section{REFERENCES}

1 Wyatt JC, Keen J. The new NHS information technology strategy. Technology will change practice. BMJ 2001;322:1378-9

2 Burns F. Information for Health, a National Strategy for Local Implementation. Leeds: NHS Executive, 1998

3 Butler P. £500m plan to plug NHS into internet revolution. Guardian 15 January 2001. [http://society.guardian.co.uk/internet/story/0,8150, $422684,00 . \mathrm{html}]$

4 Department of Health. Delivering 21 st century support for the NHS. [http://www.doh.gov.uk/ipu/whatnew/deliveringit/]

5 Department of Health. NHS Direct-on-line [http://www.nhsdirect. nhs.uk]

6 NHS Information Authority. National Electronic Library for Health [http://www.nelh.nhs.uk]

7 National Health Service. Welcome to the NHS. NHS dot UK [http:// www.nhs.uk/]

8 Department of Health Information Policy Unit. Information Security and Risk Management [http://www.doh.gov.uk/ipu/security/index2.htm]

9 Berg M. Implementing information systems in health care organizations: myths and challenges. Int J Med Inf 2001;64:143-56
10 Department of Health. Press Releases Archive [http:// www.info.doh.gov.uk/doh/intpress.nsf/SelectDate?OpenForum]

11 Free Medical Journals [http://www.freemedical journals.com]

12 Eysenbach G, Kohler C. How do consumers search for and appraise health information on the world wide web? Qualitative study using focus groups, usability tests, and in-depth interviews. BMJ 2002;324:573-7

13 Judge: Websites for Health [http://www.judgehealth.org.uk/ index.htm]

14 Rokade A, Kapoor PK, Rao S, Rokade V, Reddy KT, Kumar BN. Has the internet overtaken other traditional sources of health information? Questionnaire survey of patients attending ENT outpatient clinics. Clin Otolaryngol 2002;27:526-8

15 Larner AJ. Use of the internet and of the NHS direct telephone helpline for medical information by a cognitive function clinic population. Int J Geriatr Psychiatry 2003;18:118-22

16 Timmons $\mathrm{S}$. Use of the Internet by patients: not a threat to nursing, but an opportunity? Nurse Educ Today 2001;21:104-9

17 Greenwood J. Employing a range of methods to meet patient information needs. Prof Nurse 2002;18:233-6

18 Cheetham PJ, Le Monnier KJ, Brewster SF. Attitudes and use of alternative therapies in UK prostate cancer patients - isn't it time we were in the know? Prostate Cancer Prostatic Dis 2001;4:235-41

19 Tuffrey C, Finlay F. Use of the internet by parents of paediatric outpatients. Arch Dis Child 2002;87:534-6

20 Cargill A, Watson AR. Sources of information on renal conditions used by families. Pediatr Nephrol 2002;17:648-51

21 Noll S, Spitz L, Pierro A. Additional medical information: prevalence, source, and benefit to parents. J Pediatr Surg 2001;36:791-4

22 Smart JM, Burling D. Radiology and the internet: a systematic review of patient information resources. Clin Radiol 2001;56:867-70

23 Nicholas D, Huntington P, Williams P, Vickery P. Health information: an evaluation of the use of touch screen kiosks in two hospitals. Health Info Libr J 2001;18:213-19

24 Top 50 UK Websites [http://www.top50.co.uk]

25 Patient UK [http://www.patient.co.uk]

26 Internet Magazine. Health sites directory [http://www.internetmagazine.com/site_directory/health.asp]

27 Net Doctor [http://www.netdoctor.co.uk]

28 Contact a Family [http://www.cafamily.org.uk/index.html]

29 Wilson SM. Impact of the internet on primary care staff in Glasgow. J Med Internet Res 1999;1:E7

30 Wilson P, Droogan J, Glanville J, Watt I, Hardman G. Access to the evidence base from general practice: a survey of general practice staff in Northern and Yorkshire Region. Qual Health Care 2001;10:83-9

31 Eaton L. NHS Direct Online explores partnerships with other health organisations. BMJ 2002;324:568

32 Bessell TL, McDonald S, Silagy CA, Anderson JN, Hiller JE, Sansom LN. Do Internet interventions for consumers cause more harm than good? A systematic review. Health Expect 2002;5:28-37

33 Bateman DN, Good AM, Kelly CA, Laing WJ. Web based information on clinical toxicology for the United Kingdom: uptake and utilization of TOXBASE in 2000. Br J Clin Pharmacol 2002;54:3-9

34 de Lusignan S. Commentary: improve the quality of the consultation. BMJ 2003;326:205-6

35 Bateman DN, Good AM, Laing WJ, Kelly CA. TOXBASE: poisons information on the internet. Emerg Med J 2002;19:31-4

36 McNulty CA, Gammie SM, Weinberg JR. Antibiotic guidance on the web: an opportunity for open review. J Antimicrob Chemother 2002;49:667-9

37 Wicker P. Online education demo. How to get started! Br J Perioper Nurs 2001;11:90-1 
38 Lehmann ED, Tatti P. Using the AIDA-www.2aida.org-Diabete Simulator. Part 2: Recommended Training Requirements for HealthCarers Planning to Teach with the Software. Diabetes Technol Ther 2002;4:717-32

39 O'Carroll D, Nethercott H, Perrett A. Research and practice development in Wales. Nurs Stand 1999;14:31-2

40 Turner A, Fraser V, Muir Gray JA, Toth B. A first class knowledge service: developing the National electronic Library for Health. Health Info Libr J 2002;19:133-45

41 O'Brien C. Creating books for the National electronic Library for Health: expected barriers and useful lessons. Health Libr Rev 2000; 17:209-14

42 Poyner A, Wood A, Herzberg J. Distance learning projectinformation skills training: supporting flexible trainees in psychiatry. Health Info Libr J 2002;19:84-9
43 de Lusignan S, Pritchard K, Chan T. A knowledge-management model for clinical practice. J Postgrad Med 2002;48:297-303

44 Demeris G, Eysenbach GJ. Internet use in disease management for home care patients: A call for papers. Med Internet Res 2002;4:E6

45 Clarke G, Reid E, Eubanks D, O'Connor E, DeBar LL, Kelleher C et al. Overcoming Depression on the Internet (ODIN): A Randomized Controlled Trial of an Internet Depression Skills Intervention Program. J Med Internet Res 2002;4:e14

46 Andersson G, Stromgren T, Strom L, Lyttkens L. Randomized controlled trial of internet-based cognitive behavior therapy for distress associated with tinnitus. Psychosom Med 2002;64:810-16

47 Cellan-Jones R. The Rise and Fall of "Dot.com" Britain. London: Aurum Press, 2001

48 Eysenbach G, Wyatt J. Using the internet for surveys and health research. J Med Internet Res 2002;4:E13 